\title{
Techniques of Communication
}

\author{
M. Jayachandran ${ }^{1}$ and Manikandan ${ }^{2}$ \\ ${ }^{1}$ Eritrean Institute of Technology, Asmara, Eritrea; ${ }^{2}$ NIT-Trichy, India \\ $\mathrm{mm}$ _jayachandran@yahoo.com ${ }^{1} ; \quad$ jmk_77@gmail.com ${ }^{2}$
}

\begin{abstract}
Communication is vital in teachinglearning process. The appropriate selection and mixing of its component can help for the effective transmission of curricular material from mentor to pupils. Body language and graphics language often communicate more than verbalism. Various types of graphics and colours make communication more meaningful. ICT-driven digital communication can be an effective tool which can overtake the conventional verbal communication and blackboard and chalk techniques.
\end{abstract}

Keywords: communication, sensory channels, feedback, barriers, verbal \& non-verbal communication, effectiveness and efficiency.

\section{Introduction}

Communication is basic means to all human performance and interaction. It refers to the transmission of thoughts, information and commands by employing the sensory channels. The process of interpersonal communication is both an art and a science. The aim of this paper is to highlight the elements of communication, overcome the barriers of both verbal and non-verbal communication and thus enhance the teaching-learning process more efficient.

\section{Communication}

Communication refers to the act of communing, transmitting, imparting and exchanging thoughts, sentiments and information. One may communicate to others through spoken word and silence: body postures, gestures and facial expressions, written word and other creative forms of expression. Educationists are concerned about communication between teacher and student, between Institution and government and between peers.

Communication is a dyadic concept i.e., a two-way process. Human ability to communicate depends upon the following factors:

1.Appreciation of psychology principles

2. Thinking skills

3. Expression of skills

4. Media utilization

Attitude of the communicator plays an important role. The following three aspects of attitude are important:

1. Towards Students

2. Towards the Subject

3. Towards Oneself

Attitude towards others should be positive i.e., a sense of respect, understanding and confidence. One should demonstrate one likes for the subject and its relevance. Attitude towards self implies self-confidence, conviction and believing in what one says or does.

Model of Communication

Communication from a person to another or some other persons may me modeled in terms of sender, receivers(s) and the channels(s) of communication $^{2}$ as shown in Fig. 1. The signal

\section{Information}

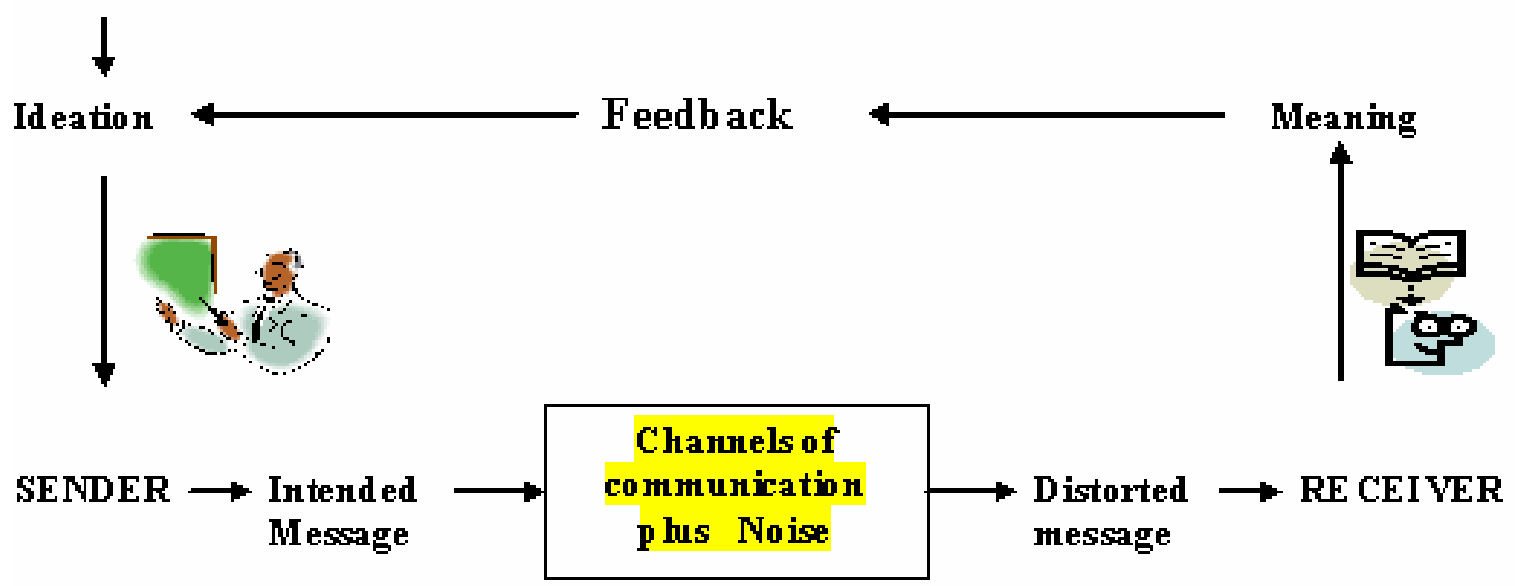

Fig. 1. Model of communication 
Indian Journal of Science and Technology

http://www.indjst.org Vol.1 No.2 (Dec. 2007)

being communicated is called the message.

\begin{tabular}{|l|l|l|}
\hline \multicolumn{3}{|c|}{ Table 1. Barriers and methods of overcoming barriers of communication } \\
\hline \multicolumn{1}{|c|}{ Types } & \multicolumn{1}{|c|}{ Barrier details } & \multicolumn{1}{c|}{ Methods of overcoming } \\
\hline $\begin{array}{l}\text { Physical } \\
\text { barriers }\end{array}$ & $\begin{array}{l}\text { Noise, invisibility, physical } \\
\text { discomfort and ill health }\end{array}$ & $\begin{array}{l}\text { - Appropriate seating arrangement } \\
\text { - Ensure audibility and visibility } \\
\text { - Provide environmental comfort }\end{array}$ \\
\hline $\begin{array}{l}\text { Language } \\
\text { barriers }\end{array}$ & $\begin{array}{l}\text { Verbalism, verbosity and } \\
\text { unclear graphics and } \\
\text { symbols }\end{array}$ & $\begin{array}{l}\text { - Use simple language and less verbalism } \\
\text { - Explain and use graphic symbols } \\
\text { - Prepare handout } \\
\text { - Use audio-visual resources }\end{array}$ \\
\hline $\begin{array}{l}\text { Psychological } \\
\text { barriers }\end{array}$ & $\begin{array}{l}\text { Disinterest, imperceptions, } \\
\text { redundancy, unrewarding } \\
\text { experience }\end{array}$ & $\begin{array}{l}\text { - Motivate listens } \\
\text { - Provide assistance and sympathy } \\
\text { - Take feedback and take corrective action }\end{array}$ \\
\hline $\begin{array}{l}\text { Background } \\
\text { barriers }\end{array}$ & $\begin{array}{l}\text { Previous learning, cultural } \\
\text { disparities }\end{array}$ & $\begin{array}{l}\text { - Catch up with individual's background } \\
\text { - Explain the importance of message } \\
\text { - Employ different methods and resources }\end{array}$ \\
\hline
\end{tabular}

The channels of communication refer to the five senses of perception. In most cases one or two channels are utilized. Often the sense of sight is underutilized and sense of hearing over utilized. In other words, the visual channels have spare capacity and the audio channel runs saturated, both operating at suboptimal efficiencies.

Further, there is "Noise" i.e., undesirable inputs due to factors called barriers into the system to diminish or distort the message. Noise may be introduced at the sender end e.g, speaker not finding the right words or stammering or writing illegible. It may rise in the channel of transmission, e.g., echo from the walls, reflection from the board or invisibility of the written word. Noise may be generated at the receiver end e.g., lack of vocabulary, inattention or imperceptions.

The various barriers of communication ${ }^{3}$ and methods of overcoming it are given in the Table 1.

\section{Dimension of Communication}

A general component of normal communication during one's interaction is given in Fig.2. It includes expression and facial expression.

From the above illustration it is understood that facial expression assumes more importance than the verbal content of a message. Vocal expression, i.e., the intonation and inflection in a spoken message also assumes more importance than the verbal content.

Appropriate gestures and posture constitute body language in communication. Facial expressions including smiling and frowning, nodding, shaking head and turning the eye have their own effect. It is better to avoid mannerism and undesirable gestures.

The most powerful of all nonverbal language is graphics. Graphical representation includes figures, charts, graphs, tables, matrices, flow diagram, schematics cartoons and pictures. Visuals are communicated in variety of ways. In print, on charts, on chalkboards, on the screen with help overhead projectors, slide projectors and computers.

Effectiveness and Efficiency

Communication is said to be effective if the intended message transmitted from the sender to the receiver. Efficiency of communication refers to the output i.e., message transmitted vis-à-vis the input, i.e., resources and time invested. Hence efficiency is related to the optimal use of the visual, aural and other channels of communication. Overcoming the barriers to communication employing the resources optimally may thus lead to improved effectiveness as well as improved efficiency of communication.

Fig.2. Oral Communication

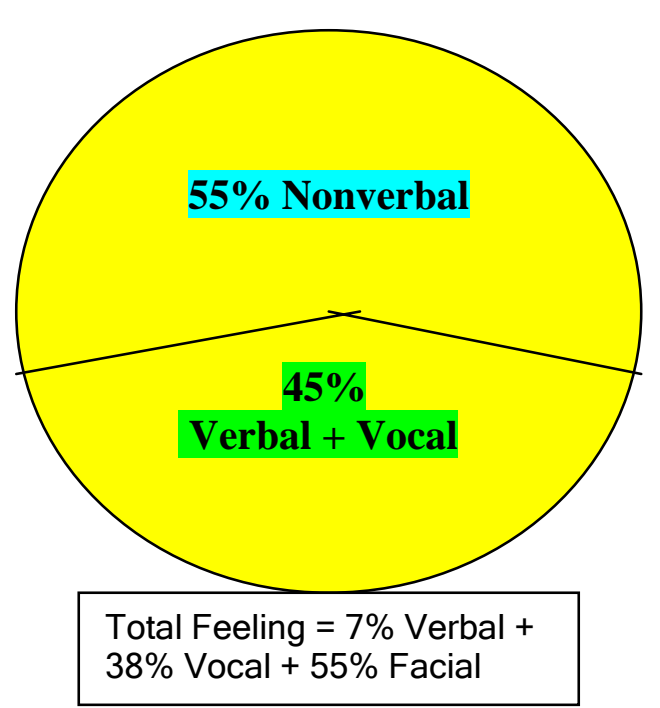




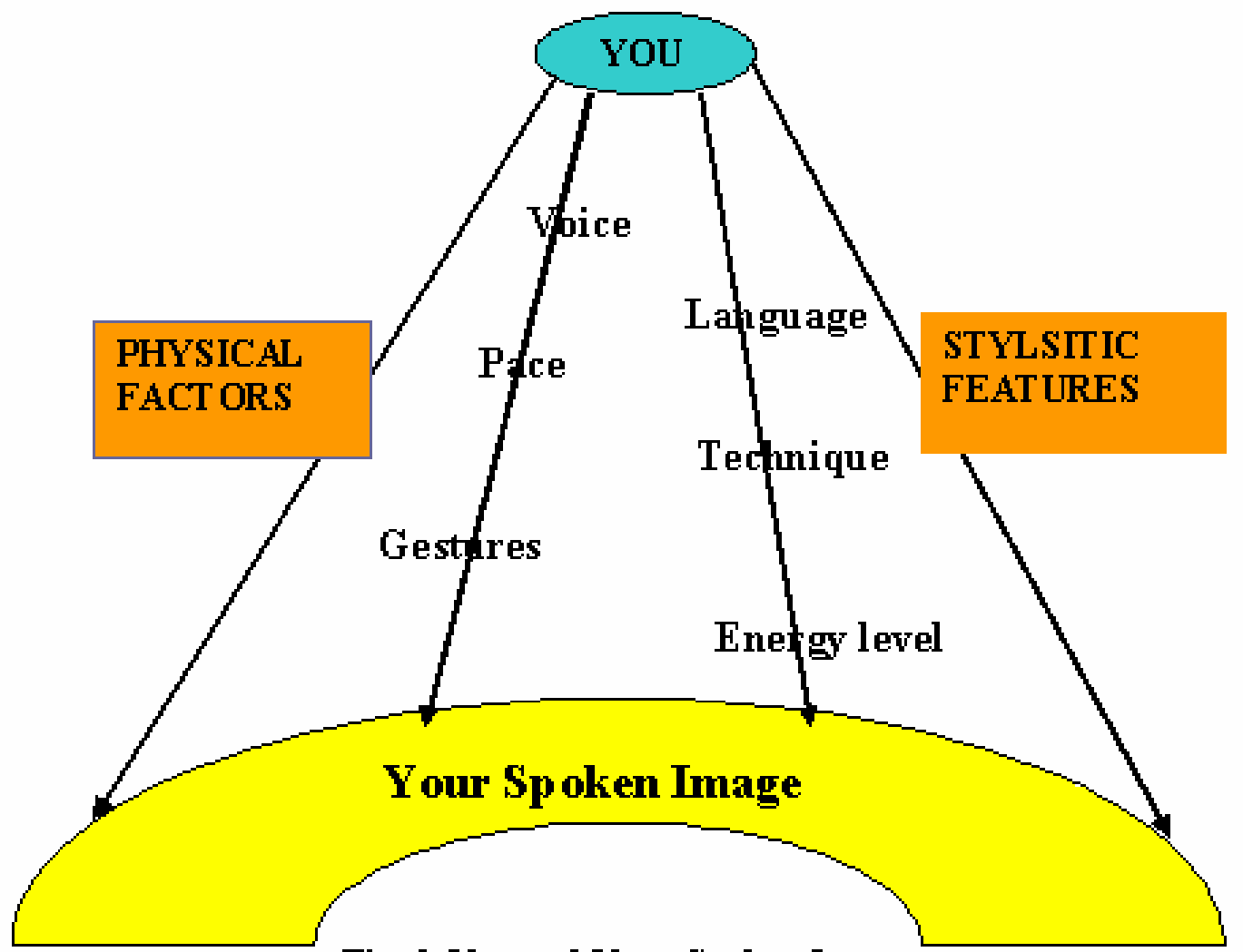

Fig. 3. You and Your Spoken Image

When you speak, you create mental picture of your personality in the audience. This is what is known a spoken image. It refers to the impact you make on the listeners i.e., on students. You can ensure your spoken image ${ }^{4}$ to be bright and clear by use the Fig. 3 .

Art of Listening

Good listeners make good communicators. Many professional do not wait and listen. Lack of listening may lead to erroneous communication.

\section{Colour and Communication}

Human eye is sensitive to different colours. Hence usage of real-life colours and appropriate to the media ensure sensory channel of communication with the brain is effective.

\section{Conclusion}

The process of communication has been dealt in order to visualize its element and barriers so that one can keep them under control and achieve high effectiveness and efficiency. Words communicate, so do different nonverbal means. Body language and graphics language often communicate more than verbalism. Various types of graphics and colours using computer aided models make communication more meaningful than the conventional black-board-chalk method.

\section{References}

1. Kumar KL (1994) Education Technologythe role: An Indian Scenario. Intn/ J. Engg. Edu. (Hamburg) 10, 76-82.

2. Singh, Ummed and Deepika (1994) Communication technology and class room Ethos, Prakshan Publn., New Delhi.

3. Kumar KL (1982) Activity analysis of teaching methodology: Frontiers in educational conference Proceedings ASEE/IEEE, pp: 212-218.,

4. Mills HR (1994) Teaching and Training, Macmillan Press Ltd ., U.K Edition. 